\title{
PERAN FKPM (FORUM KOMUNIKASI POLISI MASYARAKAT)KABUPATEN TRENGGALEK DALAMMENDUKUNG PENEGAKANHUKUM
}

\author{
Eddy Suwito ${ }^{1}$, Dyan Kristyobudi ${ }^{2}$ \\ 1. Universitas Islam Kadiri, Kediri \\ 2. Polres Trenggalek
}

\begin{abstract}
ABSTRAK
Perkembangan masyarakat saat ini yang telah masuk pada fase modern menyebabkan berkembangnya kejahatan atau tindak pidana yang mencakup jenis serta dimensi - dimensi yang sebelumnya tidak ada, semakin meningkat pola kehidupan masyarakat semakin hebat pula metode, tekhnik dan cara - cara tindak kejahatan dilakukan oleh para pelakunya. Untuk itu perlu adanya suatu upaya untuk mencegah tindak kejahatan tersebut sebagai upaya menekan laju kejahatan, baik secara preemtif, preventif maupun kuratif, yaitu penangkalan, pencegahan dan penanganan. Tidak ada kejahatan yang terlepas dan terpisah sama sekali dari lingkungan masyarakatnya Tingginya tingkat kejahatan memerlukan penanganan yang serius dengan didukung oleh profesionalisme aparat penegak hukum yang disertai jumlah personil yang memadai. Guna membantu tugas kepolisian dalam memerangi kejahatan diperlukan suatu peran serta masyarakat. Bentuk peran serta masyarakat di wujudkan dalam suatu kerjasama kemitraan melalui FKPM (FORUM KOMUNIKASI POLISI MASYARAKAT). Berdasarkan latar belakang tersebut penelitian ini mengangkat permasalahan bagaimanakah Peran FKPM (FORUM KOMUNIKASI POLISI MASYARAKAT)dalam mendukung penegakan hukum di Kabupaten Trenggalek ?.

Pendekatan masalah yang digunakan dalam penelitian ini adalah pendekatan yuridis normatif dan empiris. Pendekatan yuridis normatif, yaitu pendekatan masalah yang dilakukan dengan cara mengkaji peraturan perundang- undangan dan literatur serta bahan- bahan hukum. Pendekatan yuridis empiris, yaitu pendekatan yang dilakukan peneliti untuk mengetahui lebih jauh mengenai pelaksanaan dan penerapan serta kebijakan di lapangan terhadap kasus-kasus tertentu dari aspek hukum pidana. Sumber data yang digunakan dalam penelitian ini berasal dari lapangan dan kepustakaan. Sedangkan jenis data meliputi data sekunder dan data primer sebagai data pelengkap dan pembanding.Data sekunder adalah data-data yang diperoleh peneliti dari perpustakaan dan dokumentasi, yang merupakan hasil penelitian dan pengolahan orang lain, yang tersedia sudah dalam bentuk buku-buku atau dokumentasi yang biasanya disediakan diperpustakaan atau milik pribadi peneliti. Data primer adalah data yang diperoleh melalui penelusuran lapangan dan wawancara dengan Kepolisian, Jaksa dan hakim yang pernah menangani perkara-perkara Pasal 310, Pasal 335, dan Pasal 352 KUHP, Pasal 351 KUHP, Pasal 362 KUHP, Pasal 170 KUHP, Pasal dalam Undang-Undang nomor 23 tahun 2004 tentang Penghapusan KDRT (Kekerasan Dalam Lingkup Rumah Tangga), dan pasal dalam Undang-Undang Republik Indonesia nomor 17 tahun 2016 tentang penetapan Perpu nomor 1 tahun 2016 tentang perubahan kedua atas Undang-Undang Republik Indonesia nomor 23 tahun 2002 tentang Perlindungan anak menjadi Undang-Undang serta dengan masyarakat yang bertikai / berselisih juga dengan tokoh-tokoh (agama, pemuda, masyarakat), Kepala desa dan para pengurus FKPM (FORUM KOMUNIKASI POLISI MASYARAKAT).

Hasil penelitian dan pembahasan menunjukkan bahwa peran kegiatan FKPM (FORUM KOMUNIKASI POLISI MASYARAKAT)merupakan suatu pilihan yang tepat bagi POLRI untuk menunjukan perubahan sikap dan perilakunya selaku Polisi Sipil, walau dalam pelaksanaannya belum semua personil POLRI memahami konsep FKPM yang sebenarnya. FKPM bertujuan untuk mencegah dan menangani kejahatan dengan cara mempelajari karakteristik maupun permasalahan yang ada dalam lingkungan tertentu. FKPM memanfaatkan Sumber Daya Manusia dalam komunitas guna berbagai upaya pengendalian kejahatan. FKPM dirancang untuk membangun kendali atas kejahatan sebagai upaya bersama (Kolaboratif). Kalau diterapkan secara pantas, FKPM berusaha meningkatkan kontrol atas kejahatan dengan melibatkan mekanisme control sosial yang lebih kuat. Jadi esensi FKPM adalah tingkat kejahatan berkurang manakala kualitas kehidupan komunitasnya meningkat. Maka untuk itu keuntungan penerapan FKPM dalam menjaga Kamtibmas : Berkurangnya tindak kejahatan sehingga meningkatkan ketentraman hidup dan meningkatnya kualitas kehidupan masyarakat. Polisi semakin lebih akuntabel, efektif dan transparan. Berkaitan dengan terbentuknya FKPM wewenang mereka adalah : Mengambil tindakan Kepolisian secara proforsional dalam hal terjadinya perbuatan melawan hukum yang dipandang perlu. Menyelesaikan pertikaian ringan/pertikaian antar warga berdasarkan kesepakatan bersama antara
\end{abstract}


pihak yang berperkara/ bertikai dan bila diperlukan bersama FKPM.

Secara umum pelaksanaan FKPM di Kabupaten Trenggalek berjalan dengan baik walaupun masih banyak kekurangan. Hasil penelitian menunjukkan selama tahun 2016 sedikitnya 34 kasus-kasus pelanggaran dan tindak pidana ringan yang dapat diselesaikan melalui FKPM. Dan tahun 2017 sesiktinya 24 Kasus. Kinerja dari FKPM hendaknya perlu terus di tingkatkan dengan memberikan pengawasan dan perhatian secara konsisten. Selain itu untuk menciptakan suatu keterikatan dan kesinambungan yang kuat maka hendaknya mengadakan kerja sama dengan media massa dan LSM tertentu untuk melaksanakan pemantauan disemua kesatuan POLRI di Kabupaten Trenggalek khususnya, sebagai upaya memaksimalkan hasil analisa dan evaluasi yang dilakukan secara internal..

Kata Kunci : Forum komunikasi, Polisi, Penegakkan hukum.

\section{ABSTRACT}

The development of the current society has entered the modern phase led to the rise in crime or criminal acts that includes the type and the dimensions of the previous dimensions - no, the ever-increasing pattern of people's life is getting very good anyway method, the dwarf and the way - the way the crimes committed by the perpetrators. For it is need for an effort to prevent such crimes in an effort to depress the rate of crime, whether preventive or curative, preemtif, i.e, prevention and treatment. There is no crime apart and separate at all from the environment of the society to the bigh level of crime requires a serious handling supported by the professionalism of law enforcement officers who accompanied an adequate number of personnel. In order to help the police in fighting crime required a role as well as the community. The role of the community in the form of make in a partnership through a COMMUNICATION FORUM?

Approach to the problem that is used in this research is empirical and normative juridical approach. Normative juridical approach, that approach to a problem that is done by way of reviewing laws-invitations and literature as well as legal materials. Empirical juridical approach, namely the approach of researchers to find out more about the implementation and application of the policy as well as on the field against certain cases from the aspect of criminal law. The source of the data used in this study come from the field and library. While the types of data include data on secondary and primary data as supplementary data and comparison. Secondary data is data that is retrieved from a library researcher and documentation, which is the result of research and processing others, already available in the form of books or documentation that is usually provided or diperpustakaan privately owned researcher. Primary data is data that is obtained via a search.

Research and discussion of the results shows that the role of the activities of the FKPM (POLICE COMMUNITY COMMUNICATIONS FORUM) is an option that is right for the POLICE to show a change in attitude and behavior as the civilian police, although in practice yet all POLICE personnel to understand the concept of the actual FKPM. FKPM aims to prevent and tackle crime by way of studying characteristics as well as existing problems in certain environments. FKPM utilizing the human resources in the community to the various efforts of controlling crime. FKPM is designed to establish control over crime as a joint effort (Collaborative). If applied appropriately, FKPM trying to increase control over crime by involving social control mechanisms that are more powerful. So the essence of FKPM is a reduced crime rate, while the quality of life of communities increased. Then for that advantage in keeping the FKPM application Kamtibmas: Reduced crime sebin.

In general the implementation of Trenggalek. Regency FKPM went well even though there are still many shortcomings. The results showed during the year 2016 at least 34 cases of violations and criminal acts that can be resolved through FKPM. And the year 2017 sesiktiny 24 cases. Performance of FKPM should have to continue in the increase by providing supervision and attention consistently. In addition to creating a strong attachment to, and continuity then it should hold its cooperation with mass media and certain NGOS to carry out monitoring in all POLICE Districts in Trenggalek unity in particular, as an attempt maximizing the results of analysis and evaluation conducted internally.

Keywords: Forum Communications, police, Law Enforcement.

\section{A. PENDAHULUAN}

Perkembangan masyarakat saat ini yang telah masuk pada fase modern menyebabkan berkembangnya kejahatan yang mencakup jenis serta dimensi - dimensi yang sebelumnya tidak ada, semakin meningkat pola kehidupan masyarakat semakin hebat pula metode, tekhnik dan cara - cara tindak kejahatan dilakukan oleh para pelakunya. Karena, menurut ilmu kepolisian pada khususnya, dan sosial kriminologi pada umumnya, mempercayai bahwa kejahatan adalah cermin masyarakat yang melahirkannya. Tidak ada kejahatan yang terlepas dan terpisah sama sekali dari lingkungan masyarakatnya. Namun demikian, perkembangan dan kecanggihan tindak kejahatan juga berjalan seiring dengan kemampuan untuk mengatasi kejahatan tersebut, baik secara presentif, preventif, maupun kuartif, yaitu penangkalan, pencegahan, dan kejahatan itu sendiri, kemampuan untuk mencegah dan 
mengatasinya juga merupakan cermin dari lingkungan masyarakatnya. Banyak metode, teknik dan cara lama yang disempurnakan. Salah satu metode penangkalan, pencegahan dan penanganan kejahatan yang sesungguhnya sudah diterapkan dan hanya disempurnakan yang disebut Community Policing.

Sebagai filosofi kepolisian modern, maka POLRI dalam rangka mengimplementasikan Community Policing di masyarakat, maka dikenalah istilah FKPM (FORUM KOMUNIKASI POLISI MASYARAKAT). Namun banyak sekali pendapat yang muncul di kalangan pakar dan berbagai kalangan mengenai istilah yang tepat sehingga tercapailah suatu kesepahaman akan istilah yang diwacanakan kepada masyarakat. Maka POLRI menerbitkan SK KAPOLRI No.Pol: Skep/737/X/2005, menyatakan -Tanpa mengenyampingkan kemungkinan penggunaan penterjemahan istilah yang berbeda terutama bagi keperluan akademis, secara formal oleh jajaran POLRI, model tersebut diberi nama FKPM (FORUM $\quad$ KOMUNIKASI $\quad$ POLISI MASYARAKAT) dan selanjutnya secara konseptual dan operasional disebut FKPM. Berdasarkan Surat Keputusan itu berarti istilah FKPM merupakan singkatan KOMUNIKASI POLISI MASYARAKAT, yang diciptakan oleh beberapa komunitas dilingkungan masyarakat bersinergi dengan POLRI dan diharapkan dapat melaksanakan tugas dan fungsinya seperti komunitas yang sebelumnya ada dan biasa disebut dengan istilah Community Policing.

Konsep mengenai FKPM sangat berkaitan dengan program - program hubungan komunitas dari dekade 1950an dan 1960an di Amerika Serikat, dan berkembang guna meningkatkan interaksi antar komunitas, terutama komunitas minoritas dengan Polisi. Sekalipun konsep tersebut ada yang gagal diterapkan di sejumlah kepolisian tetapi gagasan mengenai konteks komunitas tersebut tetap berlangsung, terutama karena meningkatnya bukti bahwa model birokratik dan praktek kepolisian konvensional tidak efektif. Untuk itu FKPM dirasa cocok bila diterapkan di Indonesia mengingat akan kondisi teritorial, keanekaragaman budaya, Ras dan agama maka dirasa sangat efektif bila FKPM berpartisipasi menjaga Kamtibmas di wilayah masing - masing dengan bekerja sama dengan Polisi.

Dasar Hukum Penerapan FKPM dalam fungsi POLRI:

a. UUD 1945 Pasal 27 danperubahan kedua UUD 1945 BABXIIPasal 30

b. TAP MPR No. VI/MPR/2000, memisahkan lembaga TNI dan lembaga POLRI. TAP MPR
No. VII/MPR/2000, memisahkan peran pertahanan keamanan, keamanan menjadi peran POLRI dan pertahanan menjadi peran TNI.

c. Undang-Undang No. 8Tahun 1981 KUHAP pasal 108,111 ayat (1)

d. Undang-UndangNo. 2Tahun 2002 tentang POLRI, Pasal 14 (1)

e. UUNo, 22 Tahun 1999 tentang Pemerintahan Daerah, Pasal 43 (d,f)

f. SKEP KAPOLRI No.Pol : Skep/737/X/2005. SKEP KAPOLRI No.Pol: Skep/431/VIII/2006. SKEP KAPOLRI No.Pol : Skep/433/VII/2006.SKEP KAPOLRI No.Pol: Skep/432/VIII/2006

Tantangan (POLRI) selaku pelindung, pengayom dan pelayan masyarakat kedepan akan semakin berat. Masyarakat semakin kritis menyikapi perilaku aparat kepolisian yang tidak responsif terhadap permasalahan yang menjadi tugas dan tanggung jawabnya. Komitmen mewujudkan sosok POLRI yang dicintai masyarakat harus dapat dibuktikan melalui perubahan - perubahan yang fundamental dalam tubuh POLRI. Perubahan - perubahan dalam tubuh POLRI telah terlihat dengan adanya mutu dan kualitas pelayanan public oleh POLRI semakin hari semakin baik akibat terpangksnya sistem birokrasi dan perbaikan dukungan anggaran POLRI yang ditetapkan oleh Pemerintah Republik Indonesia. Walaupun tidak sepenuhnya anggaran yang ada mampu mendukung kegiatan kepolisian akan tetapi meningkatnya dukungan anggaran secara psikologis memotivasi personel POLRI untuk berbuat yang lebih baik.

Salah satu metode baru yang diterapkan oleh POLRI yaitu FKPM dengan mensinergikan POLRI dengan beberapa pihak dan masyarakat guna menjaga Kamtibmas. Konsep mengenai FKPM sangat berkaitan erat dengan program program hubungan komunitas dari dekade 1950an dan 1960an di Amerika Serikat, yang berkembang guna meningkatkan interaksi antar komunitas, terutama komunitas minoritas dengan polisi. Program - program tersebut berkembang terus sepanjang dekade 1970an dengan konsep tersebut ada sebagian yang dikatakan gagal diterapkan di sejumlah kepolisian, tetapi gagasan mengenai konteks forum komunitas ini tetap berjalan dengan baik, terutama karena meningkatnya bukti bahwa model birokratik dan praktek kepolisian konvensional ternyata tidak efektif.

FKPM salah satu bentuk kemitraan langsung antara kepolisian dengan masyarakat demi merubah pandangan masyarakat akan polisi yang terkesan hanya berhubungan dengan masyarakat yang jahat. Dimana pada saat ini 
ditekankan untuk mencegah tindakan kejahatan bukan bertindak setelah terjadi kejahatan. Hal itu lebih memberatkan faktor sebab kejahatan daripada akibat kejahatan demi menjaga Keamanan, ketertiban masyarakat. Hal ini salah satu tonggak perubahan wajah dan kultur POLRI yang mandiri terlepas dari cara pandang masa lalu. Pencitraan diri sosok POLRI harus diimbangi dengan meningkatkan kualitas Sumber Daya Manusia (SDM) POLRI yang semakin baik dan didukung mental spiritual dan religius. Dengan begitu, kehadiran POLRI ditengah masyarakat memberikan kesan dan sesuai dengan slogan POLRI yaitu : melindungi, mengayomi dan melayani masyarakat.

\section{Rumusan Masalah}

Berdasarkan uraian diatas, maka pokok permasalahan yang akan dibahas didalam Tesis ini adalah sebagai berikut :

Berdasarkan Latar Belakang masalah diatas dirumuskan mengenai:

1. Bagaimanakah peran FKPM dalam mendukung penegakan hukum di Kabupaten Trenggalek?

2. Apa faktor penghambat dan faktor pendukung pelaksanaan FKPM dalam mendukung penegakan hokum di Kabupaten Trenggalek?

\section{Tujuan Penelitian}

1. Untuk mengetahui peran FKPM dalam mendukung penegakan hokum di Kabupaten Trenggalek ?

2. Untuk mengetahui faktor penghambat dan faktor pendukung pelaksanaan FKPM dalam penegakan hukum di Kabupaten Trenggalek?

\section{Manfaat Penelitian}

Penelitian inimemiliki dua kegunaan, yaitu :

a. Kegunaan Teoritis

Secara teoritis hasil penelitian ini dapat digunakan untuk memperkaya kajian hukum pidana terhadap pelaksanaan dan pembentukkan forum komunikasi dan masalah - masalah yang berkaitan dengan masyarakat khususnya terkait dengan penyelesaian masalah - masalah kecil di masyarakat melalui FKPM dan faktor faktor yang mempengaruhi pelaksanaan FKPM dalam menciptakan situasi keamanan masyarakat yang kondusif.

b. Kegunaan praktis

1) Bagi masyarakat, hasil penelitian ini diharapkan dapat dijadikan masukan dan bahan pertimbangan mengenai arti penting FKPM menyelesaikan masalah masalah Tindak Pidana Ringan (TIPIRING) dan konflik horizontal yang timbul dimasyarakat dengan bijak dan adil oleh masyarakat itu sendiri.

2) Bagi POLRI, hasilpenelitian inidapat bermanfaat sebagai masukan guna meningkatkan kerjasama kemitraan dengan masyarakat dalam pembentukan FKPM guna membantu kinerja Kepolisian.

3) Bagi peneliti lainyang menelititopik sejenis, hasil penelitian ini dapat dijadikan sebagai sumber informasi danbahan pembanding yangdapat melengkapi hasilpenelitiannya.

\section{Sumber Bahan Hukum}

Sumber data yang digunakan dalam penelitian ini berasal dari lapangan dan kepustakaan. Sedangkan jenis data meliputi data sekunder dan data primer sebagai data pelengkap dan pembanding.

1. Data primer.

Data primer adalah data yang diperoleh melalui penelusuran lapangan dan wawancara dengan Kepolisian, Jaksadanhakimyang pernah menangani perkara- perkara Pasal 310, Pasal 335, dan Pasal 352 KUHP,Pasal 351 KUHP, Pasal 362 KUHP, Pasal 170 KUHP, Pasal dalam Undang-Undang nomor 23 tahun 2004 tentang Penghapusan KDRT (Kekerasan Dalam Lingkup Rumah Tangga), dan pasal dalam Undang-Undang Republik Indonesia nomor 17 tahun 2016 tentang penetapan Perpu nomor 1 tahun 2016 tentang perubahan kedua atas Undang-Undang Republik Indonesia nomor 23 tahun 2002 tentang Perlindungan anak menjadi Undang-Undang serta dengan masyarakat yang bertikai/berselisih juga dengan tokoh-tokoh (agama, pemuda), Kepala Desa dan para pengurus FKPM. Hal ini dilakukan untuk mendapatkan suatu data yang digunakan peneliti untuk membandingkan mengenai peran FKPM di masyarakat dengan peran POLISI diwilayah setempat sehingga mengetahui batasan wewenang FKPM agar tidak melebihi batas atau dapat disalah gunakan.

2. Data Sekunder

Data sekunder adalah data-data yang diperoleh peneliti dari perpustakaan dan dokumentasi, yang merupakan hasil penelitian dan pengolahan orang lain,yang tersedia sudah dalam bentuk buku-buku atau dokumentasi 
yang biasanya disediakan di perpustakaan atau milik pribadi peneliti. Data sekunder dibedakan menjadi :

a. Bahan hokum primer merupakan bahan hokum yang bersifat mengikat berupa Peraturan Perundang-undangan. dalam penelitian ini terdiri dari :

1) Kitab Undang-Undang Hukum Pidana (KUHP).

2) Kitab Undang-Undang Hukum Acara Pidana (KUHAP)

3) Undang-Undang Nomor 2 Tahun 2002 tentang Kepolisian Negara Repubik Indonesia.

b. Bahan hokum sekunder yaitu bahan hokum yang berkaitan langsung dengan masalah yang diteliti yaitu Kepolisian masyarakat, seperti Surat Keputusan KAPOLRINoPol:SKEP/737/X/2005 tentang Kebijakan dan Strategi Penerapan FKPM, Keputusan KAPOLRI No Pol: SKEP/431/VII/2006 tentang Pedoman Pembinaan Personil Pengemban Fungsi FKPM, Keputusan KAPOLRI NoPol:SKEP/432/VII/2006 tentang Fungsi-fungsi Operasional POLRI dengan Pendekatan FKPM, Keputusan KAPOLRI No. Pol : SKEP/433/VII/2006 tentang Panduan Pembentukan dan Operasionalisasi FKPM.

Bahan hokum tersier yaitu bahan hokum yang memberikan petunjuk maupun penjelasan terhadap bahan hokum primer dan bahan hukum sekunder yang lebih dikenal dengan nama acuan bahan hukum, misalnya Kamus Hukum, indeks majalah hukum, jurnal penelitian hokum dan bahan-bahan hasil pencarian data melalui internet yang berkaitan dengan masalah yang hendak diteliti.

\section{B. HASIL DAN PEMBAHASAN}

1. Strategi danProgramPengembanganFKPM a. Strategi Internal (POLRI)

b. Strategi Eksternal (Masyarakat)

c. Program Pengembangan FKPM

d. Kebijakan Penerapan FKPM

FKPM bukan hanya semacam program penyelenggaraan fungsi kepolisian tetapi merupakan metafora yang menuntut perubahan mendasar kearah personalisasi penyajian layanan kepolisian. Melalui FKPM, dapat meningkatkan akuntabilitas polisi dimana lebih mendengarkan saran, harapan, masalah, keluhan, dan kritik terhadap perilaku polisi guna mendapat kepercayaan warga. Perubahan demikianakan membawa konsekuensi dalam pelaksanaan tugas POLRI sebagai aparat penegak hukum dalam masyarakat yang demokratis. Oleh karena itu, penerapan FKPM hanya direalisasikan pada level local terutama lingkungan komunitas yang mencerminkan kehidupan bersama yang komunitarian.

\section{e. Wewenang danTugasFKPM}

FKPM adalah model penyelenggaraan fungsi kepolisian yang menekankan pendekatan kemanusiaan (bumanitic approach) sebagai perwujudan dari kepolisian sipil dan yang menempatkan masyarakat sebagai mitra kerja yang setara dalam upaya penegakan hokum dan pembinaan dan ketertibanmasyarakat. Sebagai falsafah, perwujudan FKPM merasuk dalam :

1. Sikap dan perilaku POLRI;

2. Menjunjung tinggi nilai-nilai sosial/ kemanusiaan;

3. Berkaitan dengan terbentuknya FKPM wewenang mereka adalah :

4. Mengambil tindakan Kepolisian secara proforsional dalam hal terjadinya perbuatan melawan hukum yang dipandang perlu.

5. Menyelesaikan pertikaian ringan/ pertikaian antar warga berdasarkan kesepakatan bersama antara pihak yang berperkara/ bertikai dan bila diperlukan bersama FKPM.

6. Mengambil langkah-langkah penertiban jika diperlukan sebagai tindaklanjut kesepakatan FKPM dalam memelihara keamanan lingkungan.

Adapun Tugas pokok bagi FKPM adalah:

a. Fungsi deteksi;

b. Melaksanakan fungsi menyelengarakan fungsi bimbingan dan penyuluhan masyarakat;

c. Melaksanakan tugas-tugas kepolisian umum;

d. Melakukan fungsi reserse criminal secara terbatas;

Secara garis besar,tindakan polisional,baik yang bersifat pre-emtif maupun preventif dilaksanakan secara maksimal sekaligus dibarengi dengan tindakan penegakan hokum (menangkap, menyidik, dan memproses sampai ke pengadilan para pelaku), tanpa menimbulkan gejolak sosial di masyarakat yang diikuti kegiatan rehabilitasi (penyuluhan,perbaikan sarana dan prasarana sosial,rumah penduduk, bantuan sandang dan pangan) bekerjasama dengan pemuda dan masyarakat setempat.

Melalui penerapan prinsip FKPM, maka masyarakat terlibat secara langsung didalam menjalankan tugas-tugas pemeliharaan keamanan dan ketertiban, sehingga memungkinkan warga setempat untuk memelihara dan menumbuh kembangkan 
sendiri pengelolaan keamanan dan ketertiban dilingkungan masing-masing.

\section{KESIMPULAN}

Peran FKPM (FORUM KOMUNIKASI POLISI MASYARAKAT) dalam mendukung penegakan hukum di Kabupaten Trenggalek, adalah : Menciptakan Kamtibmas dengan berkoordinasi bersama POLSEK jajaran yang ada di Kabupaten Trenggalek, dengan menyelesaikan pertikaian ringan/pertikaian antar warga berdasarkan kesepakatan bersama antara pihak yang berperkara/bertikai dan bila diperlukan bersama FKPM. Mengambil langkah - langkah awal kepolisian jika diperlukan sebagai tindak lanjut kesepakatan FKPM dalam memelihara keamanan lingkungan. Adapun Tugas pokok bagi FKPM adalah : Fungsi deteksi. Melaksanakan fungsi penyelenggaraan fungsi bimbingan dan penyuluhan masyarakat. Melaksanakan tugas-tugas kepolisian umum, fungsi reserse kriminal secara terbatas. Melaporkan setiap pelaksanaan tugasnya baik tertulis maupun lisan. Kegiatan FKPM merupakan suatu pilihan yang tepat bagi POLRI untuk menunjukan perubahan sikap dan perilaku selaku Polisi Sipil, namun dalam pelaksanaannya belum semua Anggota POLRI memahami konsep FKPM yang sebenarnya karena personil FKPM yang utama harus memiliki jiwa sosial yang tinggi, berdedikasi dan harus dalam perekonomian yang baik karena FKPM tidak diberi gaji/ tunjangan dan bias mencerminkan petugas POLRI yang humanis dengan mengedepankan slogan 3-S (Senyum, sapa, Salam).

Adapun faktor yang menghambat terciptanya FKPM ditengah masyarat adalah masih banyaknya masyarakat yang belum mengetahui konsep, peran dan fungsi FKPM ditengah masyarakat. Masih adanya rasa kurang percaya masyarakat terhadap aparat POLRI. Telah sekian puluh tahun masyarakat menilai sistem perpolisian yang cenderung militaristik. Tindakan dan perilaku aparat POLRI yang melenceng di tengah kehidupan masyarakat, tidak tegas, tebang pilih dalam penanganan kasus, yang semakin menjadikan masyarakat timbul ketidakpercayaan pada polisi. Hal inilah yang kemudian menjadi dampak dari terlaksananya FKPM ditengah masyarakat. Adapun faktor pendukung terciptanya FKPM ditengah masyarat adalah keinginan masyarakat terlibat secara langsung didalam menjalankan 175 tugas pemeliharaan keamanan dan keteruvaı, sehingga memungkinkan warga setempat untuk memelihara dan menumbuh kembangkan sendiri pengelolaan keamanan dan ketertiban dilingkungan masing-masing.

\section{DAFTAR PUSTAKA}

BUKU :

Arikunto,Suharsimi,1989.Prosedur Penelitian Suatu Pendekatan Praktik.PT.Bima Aksara-Jakarta.

Bakhri, Syamsul.2007. Hukum Kepolisian.LAKSBANG MEDIATAMA, Surabaya. $291 \mathrm{hlm}$.

Djamin, Awaloedin. 1961.Prinsip-prinsip PenuntutanPOLRI. PTIK, Jakarta. Kelana, Momo. 2004. Membangun Budaya Polisi Indonesia. Mimeo, Jakarta. Kurnato, Anton Tabah.1995. Polisi Harapan dan Kenyataan. CV. Sahabat,Klaten. $276 \mathrm{hlm}$.

Muladi.2001.Menjamin Kepastian Ketertiban Penegakan dan Pelindungan Hukum dalam era Globalisasi.Jurnal Keadilan.

Prakoso,Djoko.1986.Peranan Psikologi dalam Pemeriksaan Tersangka Pada Tahap Penyidikan. Jakarta: Ghalia Indonesia.

Rahardjo, Satjipto. 1982. Ilmu Hukum. PT. Citra Aditya Bakti, Bandung. 1983. Aneka Persoalan Hukum dan Masyarakat. Alumni, Bandung.

Soekanto, Soerjono. 1982.Penegakan Hukum.BinaCipta, Bandung. 1982.Beberapa Teori Sosiologi tentang

Struktur Masyarakat, Jakarta: Raja Grafindo Persada. 1986.Pengantar Penelitian Hukum. Jakarta: UI Press.

Sutanto, Hermawan Sulistyo, Tjuk Sugiarso. 2007. POLMAS Falsafah Baru Pemolisian. Pensil324, Jakarta.

http://de-kil.blogspot.com/2009/04/ sosiologiprespektif-realitas-sosial. Html

Hamzah, Andi,S.H.1986. Kamu sHukum ,Ghalia Indonesia,cetakan pertama, Agustus, Jakarta - hal.242-243

Rieneka Cipta.

Undang-UndangNo.2Tahun2002 Kepolisian Negara Republik Indonesia

UU No.22 Tahun 1999 tentang Pemerintahan Daerah.

Keputusan KAPOLRINo. Pol: SKEP/431/VII/2006 tentang Pedoman Pembinaan Personil Pengemban Fungsi POLMAS.

Poerwo Darminto,W.J.S, 1996. Kamus Umum Bahasa Indonesia, Balai Pustaka.

nzhar,Lalu Muhammad.1996.Supervisi Klinisdalam Penerapan Keterampilan Proses dan CBSA. Surabaya. Usaha Nasional.

Abdussalam.R.1997.PenegakanHukum di Lapangan oleb POLRI. Dinas Hukum 
POLRI.

Arikunto, Suharsimi,1989.Prosedur Penelitian Suatu Pendekatan Praktik.PT.Bima Aksara-Jakarta.

Bonger, WA, 1982. Pengantar tentang Kriminologi. PT. Pembangunan Ghalia Indonesia.

Djamin, Awaloedin. 1961.Prinsip-prinsip Penuntutan POLRI. PTIK, Jakarta.

Hadi Mulyo,1991.Hukum Militer.Penerbit Direktorat Pendidikan POLRI Pusat Pendidikan Lantas.Jakarta.

Kelana, Momo. 2004.Membangun Budaya Polisi Indonesia. Mimeo, Jakarta. Koenarto, 1997. Etika Kepolisian. PT. Gramedia, Jakarta. ------. 1992. Tren Kejahatan dan Kebijakan Penanggulangannya.Fakultas Hukum UNDIP,Semarang.

Meliono, Anton dkk. 1990. Kamus Besar Bahasa Indonesia. Jakarta. Balai

Pustaka.

Mustaji. 2001. Proses Belajar mengajar. Surabaya.FISUnesa. Pidarta, Made. 1997. Landasan Kependidikan. Jakarta. RinekaCipta.

Pidarta,Made. 1999.Pemikiran Tentang Supervisi Pendidikan .Jakarta.Bumi Aksara.

Purwanto,M.Ngalim.2001.Administrasidan Supervisi Pendidikan.Bandung.Remaja Rosdakarya.

Poernomo,Bambang,2003. Asas-Asas Hukum Pidana. Ghalia Indonesia,Cet.IV, Jakarta.

Rahardi,Pudi.2007.Hukum Kepolisian Profesionalisme dan Reformasi POLRI.Laksbang Mediatama, Surabaya.

Rahardjo, Satjipto. 1982. Ilmu Hukum. PT. Citra Aditya Bakti,Bandung. 1983. Aneka Persoalan Hukum dan Masyarakat. Alumni, Bandung.

Riyanto, Yatim. 2001. Landasan Pembelajaran. Surabaya. Program Pascasarjana Universitas Negeri Surabaya.

Sahertian,A.Piet.2000.KonsepDasardan

Tehnik Supervisi Pendidikan dalam Rangkea Pengembangan Sumber Daya manusia. Jakarta. Rineka Cipta.

Sutanto, Hermawan Sulistyo, Tjuk Sugiarso. 2007. POLMAS Falsafah Baru Pemolisian. Pensil324, Jakarta.

Hamzah, Andi.2005. KUHP dan KUHAP. Jakarta: Rieneka Cipta.

Undang-Undang No.2 Tahun 2002 Kepolisian Negara Republik Indonesia

UU No.22 Tahun 1999 tentang Pemerintahan Daerah.

Keputusan KAPOLRI No.Pol : SKEP/431/VII/2006 tentang Pedoman Pembinaan Personil Pengemban Fungsi POLMAS.
Hadi,Sutrisno,1987.Metodelogi

Reseach,Jilid1dan3Yogyakarta.YayasanPene rbit Fakultas Psikologi UniversitasGajah Mada.

Rahardjo, Satjipto. 1982. Ilmu Hukum. PT. CitraAdityaBakti,Bandung. 1983. Aneka Persoalan Hukum dan Masyarakat. Alumni, Bandung.

Soekanto, Soerjono.1986. Pengantar Penelitian Hukum. Jakarta: Penerbit Universitas Indonesia (UI-Press).

Sutanto, Hermawan Sulistyo, Tjuk Sugiarso. 2007. POLMAS Falsafah Baru Pemolisian. Pensil324, Jakarta.

Hamzah, Andi.2005. KUHP dan KUHAP. Jakarta: Rieneka Cipta.

Undang-UndangNo.2 Tahun 2002 Kepolisian Negara Republik Indonesia. Surat Keputusan KAPOLRINo. Pol: SKEP/737/X/2005 tentang Kebijakan dan Strategi Penerapan POLMAS.

Hamzah,Andi,S.H.1986.KamusHukum,Ghalia Indonesia,cetakan pertama, Agustus, Jakarta - hal.242-243

Mertokusumo, Sudikno, 1985. Mengenal bukum : suatu pengantar, Liberty, Yogyakarta,

Poerwo Darminto,W.J.S,Kamus Umum Bahasa Indonesia, Balai Pustaka.1996

Abdussalam.R.1997.PenegakanHukum diLapanganoleh POLRI.Dinas

Hukum POLRI.

Arikunto,Suharsimi,1989.Prosedur Penelitian Suatu Pendekatan Praktik.

PT.BimaAksara-Jakarta.

Bakhri, Syamsul.2007. Hukum Kepolisian. LAKSBANG MEDIATAMA, Surabaya. $291 \mathrm{hlm}$.

Bonger, WA, 1982. Pengantar tentang Kriminologi. PT. Pembangunan

Ghalia Indonesia.

Djamin, Awaloedin. 1961.Prinsip-prinsip PenuntutanPOLRI. PTIK, Jakarta.

Faal.M,1991.Penyaringan Perkara Pidana Oleh Polis i(Diskresi Kepolisian). PT. Pradnya Paramita, Jakarta.

HadiMulyo,1991.Hukum Militer.Penerbit Direktorat Pendidikan POLRI Pusat Pendidikan Lantas.Jakarta.

Kelana, Momo. 2004.Membangun Budaya Polisi Indonesia. Mimeo, Jakarta. Koenarto, 1997. Etika Kepolisian. PT. Gramedia, Jakarta.

Kurnato, Anton Tabah.1995. Polisi Harapan dan Kenyataan. CV. Sahabat, Klaten. 276 hlm.

Saleh, Roeslan, 2000.Hukum Pidana Indonesia.Pradnya Paramita, Jakarta 
1983. Aneka Persoalan Hukum dan Masyarakat. Alumni, Bandung.

Sutanto, Hermawan Sulistyo, Tjuk Sugiarso. 2007. POLMAS Falsafah Baru

Pemolisian. Pensil-324, Jakarta.

Solidiki,Achmad,2001.Penegakan Hukum di Indonesia dan Aspek-aspeknya.

Erlangga, Jakarta.

Soerjono. 1982.Penegakan Hukum.BinaCipta, Bandung.

Abdussalam.R.1997.Penegakan Hukum di Lapangan oleb POLRI.Dinas

Hukum POLRI.

Arikunto,Suharsimi,1989.Prosedur Suatu Pendekatan Praktik.

PT.Bima Aksara-Jakarta.

Bakhri, Syamsul.2007. Hukum Kepolisian. LAKSBANG MEDIATAMA, Surabaya. $291 \mathrm{hlm}$.

Sutanto, Hermawan Sulistyo, Tjuk Sugiarso. 2007. POLMAS Falsafah Baru

Pemolisian. Pensil-324, Jakarta.

Soekanto, Soerjono. 1982. Penegakan Hukum.Bina Cipta, Bandung.

Kurnato, Anton Tabah.1995. Polisi Harapan dan Kenyataan. CV. Sahabat, Klaten. 276 hlm.

Hamzah, Andi.2005. KUHPdan KUHAP. Jakarta: RienekaCipta.

Undang-UndangNo.2Tahun2002 Kepolisian Negara Republik Indonesia. UUNo.22 Tahun 1999 tentangPemerintahan Daerah.

Keputusan KAPOLRINo. Pol: SKEP/431/VII/2006 tentang Pedoman PembinaanPersonil Pengemban Fungsi POLMAS.

Keputusan
SKEP/432/VII/2006 tentang Fungsifungsi Operasional POLRIdengan Pendekatan FKPM (Forum Komunitas Polisi Masyarakat).

Sudarto. 1983. Hukum Pidana dan Perkembangan Masyarakat. Sinar Baru, Bandung.

Muladi.2001.Menjamin Kepastian Ketertiban Penegakan dan Pelindungan

Hukum dalam era Globalisasi.Jurnal Keadilan.

Hamzah, Andi.2005. KUHP dan KUHAP. Jakarta: RienekaCipta.

UUD 1945 Pasal 27 danperubahan kedua UUD 1945 BABXIIPasal 30.

Undang-Undang No.2 Tahun2002 Kepolisian Negara Republik Indonesia. UUNo.22 Tahun 1999 tentang Pemerintahan Daerah.

TAPMPR No. VI/MPR/2000, memisahkan lembaga TNI dan lembaga POLRI.

TAP MPR No. VII/MPR/2000, memisahkan peran Pertahanan Keamanan, Keamanan menjadi Peran POLRIdan Pertahanan menjadi peran TNI.

Keputusan KAPOLRINo. Pol: SKEP/431/VII/2006 tentang Pedoman Pembinaan

Personil Pengemban Fungsi FKPM (Forum Komunitas Polisi Masyarakat).

Keputusan KAPOLRI No. Pol: SKEP/432/VII/2006 tentang Fungsifungsi Operasional POLRI dengan Pendekatan FKPM (Forum Komunitas Polisi Masyarakat).

Keputusan KAPOLRI No. Pol: SKEP/433/VII/2006 tentang Panduan

Pembentukan dan Operasionalisasi FKPM (Forum Komunitas Polisi Masyarakat). 